\title{
Using Spatial Models to Target Conservation Efforts for the Endangered American Burying Beetle
}

\author{
Luke A. Bell ${ }^{1, *}$, Priscilla H. C. Crawford ${ }^{2}$, Anita L. Barstow ${ }^{1}$, Chris D. Tanner ${ }^{1}$ and Dixie L. Porter ${ }^{1}$ \\ ${ }^{1}$ Fish and Wildlife Biologist, U.S. Fish and Wildlife Service, 9014 E $21^{\text {st }}$ Street, Tulsa, OK 74129, USA \\ ${ }^{2}$ Conservation Specialist, Oklahoma Biological Survey, University of Oklahoma, 111 E. Chesapeake St. Norman, OK \\ 73019, USA
}

\begin{abstract}
Numerous studies have demonstrated that using ecological models is beneficial in recovering species listed under the Endangered Species Act (ESA). In addition, many federal agencies and environmental organizations have recommended using strategic approaches to conservation. One rare species in need of conservation is the American burying beetle (ABB, Nicrophorus americanus). The ABB was listed as endangered in 1989 and conservation efforts need to be targeted and improved to be successful in achieving de-listing. We combined presence/absence ABB surveys (1979- 2011), with habitat-based model projections, to identify specific habitats where the ABB is likely to occur. Our habitat based range for the $A B B$ was $96.9 \%$ accurate in identifying positive ABB surveys $(n=485)$ from 1979 to 2011. Previously, potential ABB habitat was identified using political or county boundaries and was not precise and also included areas that were unsuitable for ABB habitat. Using spatial data, known locations, and model projections, we reduced the potential habitat range by over 4.5 million acres (1.8 million hectares) from the county delineation, resulting in greater precision for conservation of the $\mathrm{ABB}$, more targeted conservation efforts, and reduced costs to other federal agencies and industry that are required to have minimal impact to this endangered species under the ESA. Our approach will be useful to other agencies and other states that need to target conservation and recovery efforts for rare invertebrates.
\end{abstract}

Keywords: Distribution, beetle, maximum entropy, Nicrophorus, strategic habitat conservation, endangered.

\section{INTRODUCTION}

Congress enacted the Endangered Species Act (ESA) in 1973 , and as of July 2012, 1,398 species were listed as threatened or endangered and 55 species were delisted [1]. Two of the goals of the ESA, are to prevent extinction of listed species and to recover species to the point of delisting [2-4]. The National Research Council [4] stated that predictive population models were extremely useful and recommended using models whenever possible to address listing and delisting policy decisions for rare species. Williams et al. [5] concluded that making any prediction about the effect of some action on a species required a model of the system or population dynamics. More recently, McGowan and Ryan [6] stated that population models were useful tools for evaluating conservation strategies for endangered species.

While the ESA is an important legislative tool for the protection of threatened and endangered species in the United States, it sometimes conflicts with the interests of private industry, local governments, or private citizens on private and public lands $[3,4]$. Given the reality of limited or decreased federal funding, increasing needs for accountability, and multiple demands for limited natural resources, it is necessary and beneficial to use the most effective, efficient,

*Address correspondence to this author at the Fish and Wildlife Biologist, U.S. Fish and Wildlife Service, 9014 E 21st Street, Tulsa, OK 74129, USA; Tel: 918-382-4552; Fax: 918-581-7467; E-mail: Luke_Bell@fws.gov and strategic approaches to conservation for endangered species [7-10]. Many environmental organizations have recognized the need to be more strategic in the conservation of natural resources $[11,12]$.

As federal budgets decline and demands for energy increase, the U.S. Fish and Wildlife Service (Service) is witnessing ever-increasing challenges to balancing the conservation of rare species with competing demands for development [10]. For example, in states such as Oklahoma with significant oil and gas resources [13, 14], minerals [15], wind farm potential [16], and associated transmission lines, the competing interests of private industry often conflict with attempts to conserve and recover an endangered invertebrate, such as the American burying beetle Nicrophorus americanus (Olivier). In addition, climate change models indicate that temperatures will increase in Oklahoma in the future [17] and this may present additional challenges to conservation of endangered species [18, 19].

Documentation of habitat use and potential habitat is especially crucial in efforts to conserve endangered species [20]. Managers may need to examine the quantity and quality of available habitat for a particular species, and they must be able to measure features of the habitat that relate to the presence of animals $[5,6]$. Habitat models provide a scientific and accurate approach to predict species distributions [21-25]. Presence and absence data for a species may be combined with predictive models to accurately estimate a species habitat range [26, 27]. 
Listed as endangered in 1989 [28], the American burying beetle (ABB), was historically widespread throughout eastern North America and occurred in 35 states in the U.S. and three Canadian provinces [29]. However, estimates of ABB numbers have declined and remnant populations occur in only six states $[30,31]$. Many endangered species have specific habitat requirements [3], and unfortunately, this has led to the extinction of many of these species despite conservation and recovery activities [32]. However, not all extinctions can be traced to habitat specificity and some species with a wide distribution have still become rare or endangered and some have gone extinct [33]. The ABB has been found in a variety of habitats including grasslands, open fields, oak-pine woodlands, oak-hickory forests, and edge habitats [34], and some researchers have stated the ABB is a habitat generalist $[29,35]$. The ABB spends much of its life-cycle underground tending its young during summer months or inactive underground during the winter months [34].

Previously, delineation of the ABB habitat range was based on political boundaries, including state and county lines. However, defining the range of this rare species by simply using a political boundary is arbitrary and not precise. In assessing habitat for rare species, both biotic and abiotic factors need to be considered [26, 36-38]. Furthermore, the Service has stated that the best available science must be used in an adaptive management approach to conserve rare species $[8,10]$.

Recent analyses by Crawford and Hoagland [39] have provided innovative ecological approaches that combine ABB survey data from 1979 to 2008, with spatial models. These models were based on presence/absence data from surveys and were correlated to ecological predictors such as soils, vegetation, land cover, forest cover, temperatures, precipitation, geology, elevation, slope and related factors. Jaynes [40] developed a probability distribution and statistical approach to maximum entropy which generated the least biased geographic estimate possible given incomplete information. Using maximum entropy, Crawford and Hoagland [39] tested several modeling techniques to determine which produced the best map of potential ABB habitat in eastern Oklahoma. Here we applied the best model developed by Crawford and Hoagland [39] to modify the predicted range for the ABB in support of Strategic Habitat Conservation [8, 9] and we developed a more precise, biologically based habitat range for the $\mathrm{ABB}$. More accurate information for the $\mathrm{ABB}$ is important to ABB recovery, survival, and future delisting under the ESA.

Our objectives were to: 1) combine known occurrences of the ABB with predictive models and peer-reviewed literature, to develop a biologically based habitat range; and 2) develop an adaptive management approach to expand or contract ABB habitat range based on future occurrence data or changes in habitat features related to climate change or changes in other biotic and abiotic factors.

\section{MATERIALS AND METHODS}

Using Crawford and Hoagland's [39] Maximum Entropy model (Maxent) and results from ABB field surveys from 1979-2011 $(\mathrm{n}=1,822,485$ positive ABB surveys and 1,337 negative $\mathrm{ABB}$ surveys), we delineated a Habitat Based
Range (HBR) for the ABB. Our ABB field survey dataset contained information from the Oklahoma Biological Survey, Camp Gruber, and the Oklahoma Ecological Service Field Office's construction related project surveys used to detect $\mathrm{ABB}$ presence. All ABB presence surveys were conducted for a minimum of three nights in accordance with the Service's ABB presence/absence survey guidelines [41]. Survey results were considered positive if one $A B B$ was found during the three night survey, and negative if no ABBs were found.

In 2010, a study was conducted to evaluate multiple habitat predicting models for the ABB in Oklahoma [39]. Crawford and Hoagland [39] used multiple environmental factors (e.g. topographic, vegetation and landcover, and climatic) to compare multiple modeling techniques and determined the Maxent model produced the best results for predicting ABB presence in Oklahoma. We chose the Crawford and Hoagland's [39] Maxent model to develop our range. The results were spatially displayed as a map of the predicted habitat attributed with the percent likelihood of ABB presence. Predictions from this model were continuous and ranged from 1\%-99\% percent. Several studies have examined threshold choices from models as species presence indicators [42-47]. Wilson [47] identified several different methods in which thresholds can be applied to make decisions about the likelihood of a species' presence or absence. We used Wilson's [47] "method 1" approach, that assumed all modeled values $\geq 50 \%$ represented a species' presence, to determine a threshold for developing our HBR for ABBs. This approach, of using model values $\geq 50 \%$, is consistent with other invertebrate habitat modeling efforts [48, 49].

Using $50 \%$ as the threshold, we established a two mile $(3.22 \mathrm{~km})$ buffer for each pixel value $\geq 50 \%$. We chose 3.22 $\mathrm{km}$ since it represented the 1.67 mile $(2.69 \mathrm{~km})$ mean nightly movement of the $\mathrm{ABB}$ rounded to the next higher integer [50]. Since little information is known about the ABB's home range, site fidelity, or other life history needs concerning area requirements of habitat, we assumed that $\mathrm{ABBs}$ would have a tendency to remain within and among $3.22 \mathrm{~km}$ of the environmental variables that influenced the model's performance.

Johnson and Gillingham [51] described how expert-based opinion was used effectively in developing predictive habitat models. Therefore, we consulted with numerous ABB researchers and incorporated their expert opinions in developing our habitat range model. In addition, Phillips and Dudik [52] stated that it was important to develop guidelines for producing the most accurate models of species' distributions. Elith et al. [53] reported that it was important to identify and quantify any problems with modeling data that might affect the output. We found that buffering pixels produced several modeling artifacts. Therefore, we developed a definition for each artifact and a set of parameters to use to include or exclude model artifacts (Table 1). We used the $3.22 \mathrm{~km}$ distance statistic in our artifact decision making process. Artifacts, for the purposes of this study, were identified as outliers, gaps, protrusions, or inlets. The definitions of these modeling artifacts were: 1) outliers were buffered pixels that were disconnected from the contiguous HBR; 2) gaps were hollow areas within the HBR that did not occur within 3.22 
Table 1. Decision Making Strategy to Include or Exclude Artifacts in the Development of the Oklahoma American Burying Beetle (ABB) Habitat Based Range.

\section{Positive ABB Surveys}

1) Inclusion Parameter - All positive surveys, within $8.0 \mathrm{~km}$ of the modeled range, were buffered $8.0 \mathrm{~km}$ and incorporated into the final modeled range

2) Inclusion Parameter - Exists on usable space (e.g. native vegetation)

1) Exclusion Parameter - Positive survey record is $>8.0 \mathrm{~km}$ from any model value $\geq 50 \%$

2) Exclusion Parameter - No other positive survey records within $8.0 \mathrm{~km}$

3) Exclusion Parameter - Negative survey results are within $8.0 \mathrm{~km}$ of positive survey record for multiple years

Outliers

1) Inclusion Parameter - If outlier is $\leq 3.22 \mathrm{~km}$ from the modeled range

2) Inclusion Parameter - Exists on usable space (e.g. native vegetation)

1) Exclusion Parameter - Exists on unusable space (e.g. metropolitan area, lake, etc.)

2) Exclusion Parameter - Outlier is $>3.22 \mathrm{~km}$ away from the contiguous modeled range and has negative surveys between the outlier and the modeled range

3) Exclusion Parameter - No other positive survey records within $8.0 \mathrm{~km}$

4) Exclusion Parameter - If by including the outlier, a larger area would have to be filled based on the $3.22 \mathrm{~km}$ parameter

Gaps

1) Inclusion Parameter - If the width or length of the gap is $\leq 3.22 \mathrm{~km}$ across

2) Inclusion Parameter - Exists on usable space (e.g. native vegetation)

1) Exclusion Parameter - Exists on unusable space (e.g. metropolitan area, lake, etc.)

2) Exclusion Parameter - If the width and length of the gap is $>3.22 \mathrm{~km}$ across

3) Exclusion Parameter - Contains only negative survey results for multiple years

Protrusions

1) Inclusion Parameter - No surveys conducted within $8.0 \mathrm{~km}$

2) Inclusion Parameter - Exists on usable space (e.g. native vegetation)

1) Exclusion Parameter - Contains only negative survey results within $8.0 \mathrm{~km}$ of protrusion for multiple years

2) Exclusion Parameter - Exists on unusable space (e.g. metropolitan area, lake, etc.)

Inlets

1) Inclusion Parameter - All inward extensions $\leq 3.22 \mathrm{~km}$ wide and $\geq 3.22 \mathrm{~km}$ deep into the modeled range

2) Inclusion Parameter - Exists on usable space (e.g. native vegetation)

1) Exclusion Parameter - Exists on unusable space (e.g. metropolitan area, lake, etc.)

2) Exclusion Parameter - All inward extension $>3.22 \mathrm{~km}$ wide and $<3.22 \mathrm{~km}$ deep into the modeled range

$\mathrm{km}$ of any pixel values $\geq 50 \%$ and were approximately 3.22 $\mathrm{km}$ long or $3.22 \mathrm{~km}$ wide; 3 ) protrusions were finger like projections extending out from the HBR that were approximately $6.44 \mathrm{~km}$ (buffering width of pixels based on $3.22 \mathrm{~km}$ ABB movement distance) wide and were approximately 6.44 $\mathrm{km}$ long; and 4) inlets were inward extensions $\leq 3.22 \mathrm{~km}$ wide and $\geq 3.22 \mathrm{~km}$ deep into the HBR. After we defined and identified these modeling artifacts, we developed a set of parameters for including or excluding information into our HBR (Table 1). Artifact types were constructed using on- screen digitizing through ArcInfo GIS ${ }^{\mathrm{TM}}$ ver. 10.0 software. These parameters were used to finalize our HBR and will allow us to either expand or contract the HBR as new ABB survey data becomes available.

Although a high percentage of the positive ABB survey results fell within our initial HBR (i.e. before artifacts were adjusted), we wanted to account for ABB mobility; therefore, we used our parameters from Table 1 to improve our final ABB HBR. For example, we connected isolated buffered pixels (outliers) to the nearest part of the range based on 
inclusion parameters defined in Table $\mathbf{1}$, and then minimized the gaps within the habitat range if the areas were separated by approximately $3.22 \mathrm{~km}$ [50] because ABBs may travel that distance across even unsuitable habitat. However, not all outlying buffered pixels were included. For instance, we excluded one isolated buffered pixel in Johnston County, if by including it; the outcome would have produced a larger unsuitable area (i.e. $\geq 3.22 \mathrm{~km}$ ).

For the positive ABB surveys that occurred outside and within five miles $(8.0 \mathrm{~km})$ of our initial HBR, we applied a spatial buffer distance of $8.0 \mathrm{~km}$ to these locations and included these buffered areas into our HBR. This distance represented an average maximum ABB movement distance [50] rounded to the nearest integer and is a commonly reported maximum distance value in Service ABB decisions. A positive $A B B$ survey result was the strongest evidence of beetle presence; therefore, we placed more weight on positive $A B B$ survey results than on buffered pixel values in creating our HBR. For example, we buffered positive ABB surveys based on a maximum beetle movement distance and required that all of our exclusionary parameters were met before we excluded any positive ABB survey result from our final HBR. Pixels values $\geq 50 \%$ were buffered with a shorter distance than positive $\mathrm{ABB}$ surveys and we did not require that all possible exclusionary parameters be met. For positive ABB surveys that occurred within the HBR, we buffered those surveys by $8.0 \mathrm{~km}$ to fill gaps and inlets on the HBR. However, we excluded one positive $\mathrm{ABB}$ survey in Johnston County from the $8.0 \mathrm{~km}$ buffer analysis, due to the heavy sampling efforts with negative $\mathrm{ABB}$ surveys to the north and south, and we excluded two positive ABB surveys in northeast Oklahoma because they met all the exclusionary parameters in Table 1. Using the parameters established in Table 1, along with information from the scientific literature and expert opinion, we grouped the model artifacts by category for inclusion or exclusion in the final ABB HBR (Table 2). Lastly, we averaged the distance of the artifacts within each category and reported the means and the ranges (Table 2).

\section{RESULTS}

The previous county based $\mathrm{ABB}$ range included $17,169,096.62$ acres $(6,948,086.89$ hectares $)$ compared to the biologically based range of $12,642,904.95$ acres
$(5,116,402.11$ hectares $)$ or a reduction of $4,526,191.67$ acres $(1,831,684.78$ hectares). In addition, our findings indicated that the HBR for the ABB should be expanded into portions of nine additional counties (e.g. Marshall, Love, Carter, Murray, Garvin, McClain, Cleveland, Pottawatomie and Adair counties) that were previously not included in the county based range (Fig. 1).

Using the Maxent model, the predictive strength of our initial HBR was verified by the high percentage $(96.9 \%, \mathrm{n}=$ 470) of positive ABB surveys found within the HBR (Fig. 2). Out of all the negative ABB surveys ( $\mathrm{n}=1,337), 64.7 \%$ $(\mathrm{n}=865)$ were negative findings inside the initial HBR and $35.3 \%(\mathrm{n}=472)$ were outside the initial HBR. Only $3.1 \%$ (n $=15$ ) of the positive ABB surveys were found outside the initial HBR.

After we applied our set of inclusionary and exclusionary parameters (Table 1) to correct artifacts and to improve our final HBR, our predictive ability improved to $99.6 \%(\mathrm{n}=$ 483). All positive ABB survey results fell within our final HBR except two locations. Three outliers were excluded because they were within metropolitan areas and three other outliers were excluded because they were on a lake. In addition, three more outliers were excluded based on exclusionary parameters one and two and one outlier was excluded because of exclusionary parameter three in Johnston County (Table 1). Of the two protrusions in our HBR, we included one protrusion because it met the inclusionary parameters one and two and one protrusion was excluded because of exclusionary parameters one and two in Rogers County.

We included or excluded modeling artifacts based on biologically based parameters (Table 2). For example, of all positive surveys, two were excluded because they met all three exclusionary parameters for positive surveys. When we buffered positive locations by $8.0 \mathrm{~km}$, there was overlap with the several inlet areas, so we lumped inlet areas and positive buffered locations for reporting purposes (Table 2). Nothing identified as a gap was excluded from our analysis and every area that could be identified as an inlet was included into the final HBR. Lastly, based on expert opinion, we connected the Osage County HBR with an $8.0 \mathrm{~km}$ wide corridor to the rest of the HBR because these two parts of the HBR were only separated by $8.0 \mathrm{~km}$, adding $8,909.6$ ha to the overall final HBR.

Table 2. A Summary of All Identified Modeling Artifacts and Our Determination About Their Inclusion or Exclusion for Oklahoma's American Burying Beetle Habitat Based Range

\begin{tabular}{|c|c|c|c|c|c|c|}
\hline Artifact Type & \multicolumn{3}{|c|}{ Mean (ha) } & \multicolumn{3}{|c|}{ Area Range (ha) } \\
\hline Inlets Included & $5,247.8$ & \pm & $1,112.2(31)$ & 373.3 & - & $33,394.0$ \\
\hline Outliers Excluded & $4,959.5$ & \pm & $768.9(9)$ & $3,325.5$ & - & $10,414.5$ \\
\hline Protrusions Excluded & $10,153.1$ & \pm & $2,249.4(2)$ & $7,903.7$ & - & $12,402.5$ \\
\hline Protrusions Included & $12,649.2$ & \pm & $1,816.3(2)$ & $10,832.8$ & - & $14,465.5$ \\
\hline
\end{tabular}



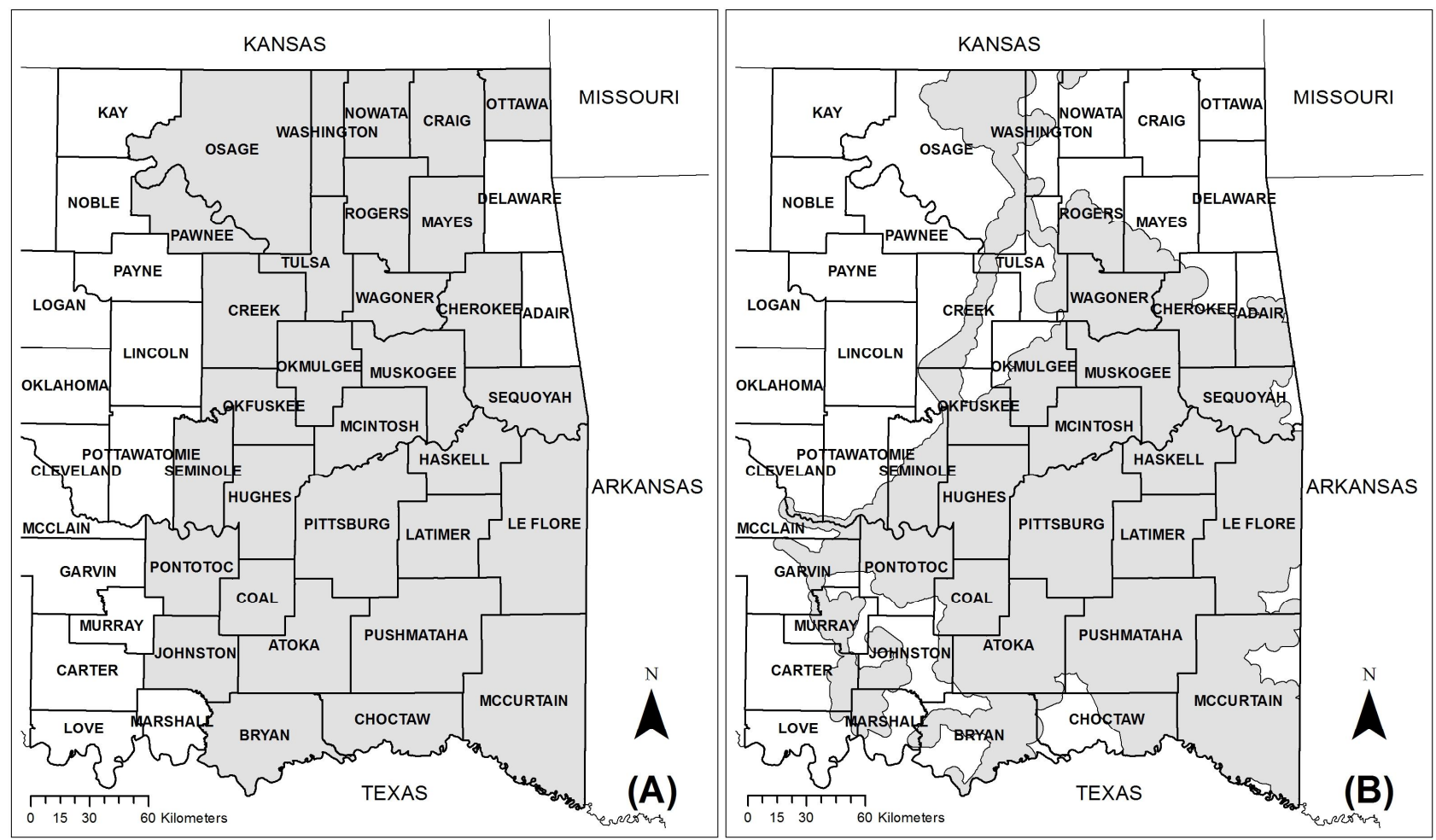

Figs. (1). Range Maps. A) Previous county based American burying beetle range map in eastern Oklahoma; B) New model based American burying beetle Habitat Based Range map in eastern Oklahoma.

\section{DISCUSSION}

To conserve endangered species given the challenges of climate change, invasive species, wildlife diseases and other uncontrollable factors, biologists must employ every available tool at their disposal to be most effective in their conservation efforts [19, 54-56]. Using knowledge of spatial distributions of rare species, and the ecological factors that affect them, is critical to conservation efforts [57-59]. A key tool to predict the effects of various factors to rare species are ecological models [60-62] or habitat models [22, 25].

Numerous studies have shown that using Maxent methodology is useful in predicting faunal distributions [40, 52, 63-65] and aiding conservation activities. For example, Baldwin [65] found that Maxent data is relatively insensitive to spatial errors associated with location data and performed better than using presence-only models. Our approach of combining a Maxent model [39], with ABB locations, scientific literature, and expert opinion, allowed us to more precisely identify areas where federal agencies and private industry should consider ABB habitat than the previous county based approach. The approach we suggest incorporated adaptive management and will be re-evaluated as new information (e.g. new landcover, new literature, additional ABB survey data, or climate change impacts) becomes available. We found that the ABB HBR derived from the Maxent model produced reasonable results when verified with Oklahoma's ABB presence survey dataset. Most importantly, the HBR correctly identified areas where ABBs were found, which demonstrated the predictive strength of the Crawford and Hoagland's [39] Maxent model with current knowledge of the species in Oklahoma. Additionally, our potential HBR helped identify additional areas where new $\mathrm{ABB}$ occurrences may be found and further prioritized potential survey locations.

Given that the $\mathrm{ABB}$ is an annual species and dependent on abiotic and biotic factors such as precipitation, soil, and temperature [39], having an adaptive approach is important and necessary. For example, with climate change, even under the lowest projected emissions scenario, it is projected that much of eastern Oklahoma will become hotter over the next 50 years [66]. Using political boundaries to prioritize ABB conservation and recovery is not strategic, nor is it the best conservation strategy to monitor threats from climate change for any species. However, climate change is only one concern. With the increased demands for development, some places will lose their ability to support plants and animals because of the fragmentation associated with development [29]. Our adaptive approach allows scientists to modify habitat predictions for $\mathrm{ABB}$ given the uncertainties of climate change and increasing development pressures and to target conservation and recovery for other threatened and endangered species.

Using the ABB HBR that we have developed for Oklahoma, conservation efforts to protect the $\mathrm{ABB}$ can be better focused on an ecologically meaningful basis rather than simply using political boundaries. The county delineation of potential habitat for the ABB was approximately 4.5 million acres (1.8 million hectares) greater and was neither precise nor helpful in targeting conservation or recovery efforts. The 


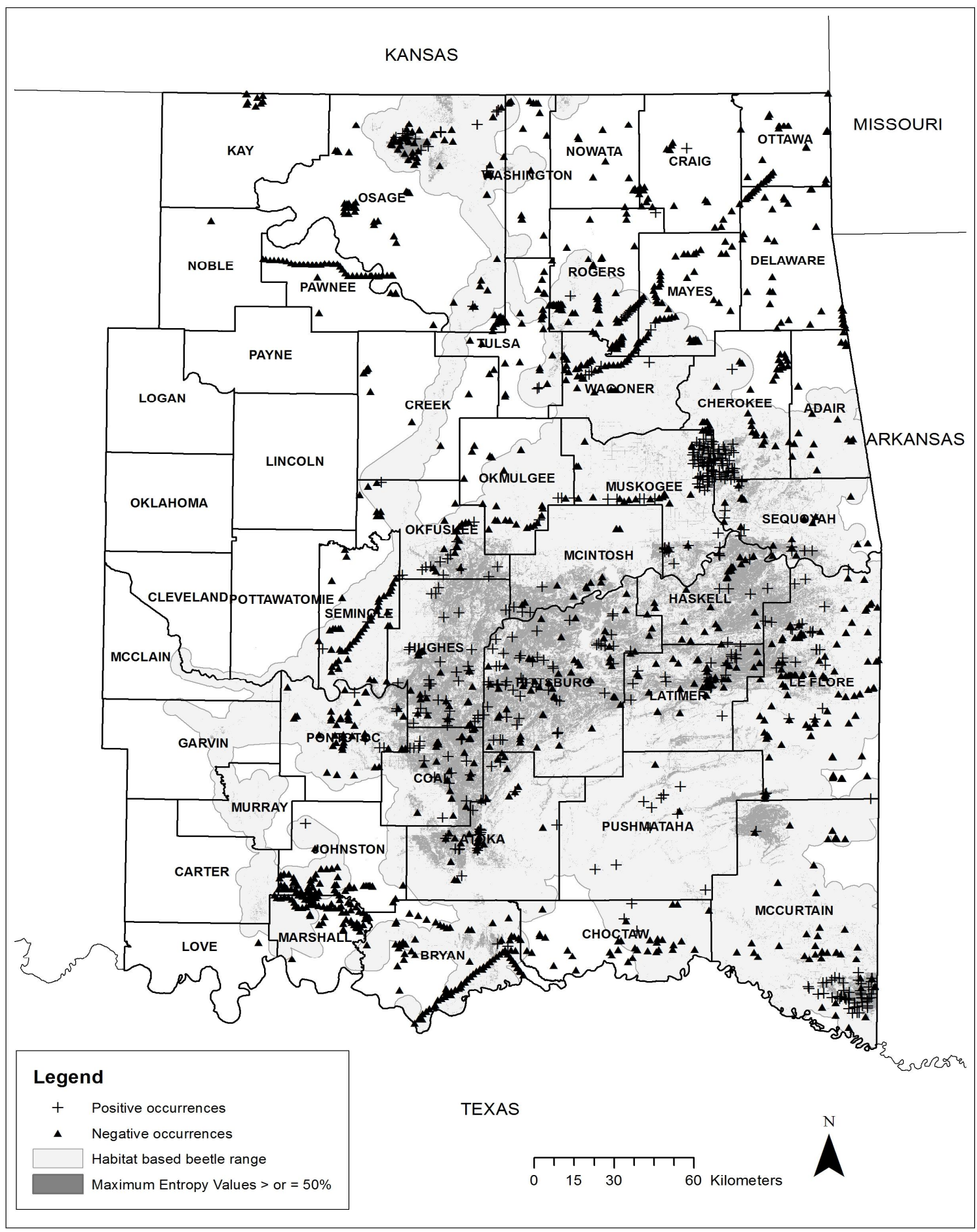

Fig. (2). Maxent Model values $\geq 50 \%$ (Crawford and Hoagland 2010) and American burying beetle Habitat Based Range map superimposed with positive and negative American burying beetle occurrences from 1979-2011 ( $\mathrm{n}=1,822)$.

new HBR provides a more specific delineation of ABB habitat, including the potential impacts from development and areas of conservation significance. Numerous federal, state, and non-governmental agencies have identified the need for strategic and targeted conservation $[8,11,12]$. Our model will encourage greater efficiency in $\mathrm{ABB}$ conservation in Oklahoma by concentrating efforts in locations that are ecologically relevant to the $\mathrm{ABB}$.
Using spatial data and model projections in combination identifies more accurate and precise habitat for rare species than simply using broad political boundaries such as counties. Given the economic conditions we currently face, it is critical that all parties involved with conserving and minimizing impacts to rare species use the most accurate predictions of species occurrence and habitat to have the greatest cost/benefit ratio. 
Our study demonstrated that the habitat suitability for an endangered invertebrate can be accomplished using GIS applications and modeling tools. Future research should be targeted to determine how climate change and fragmentation from various development pressures would impact the recovery of the ABB in the face of increasing demands from energy development. In addition, to strengthen future predictive models, a random range wide sampling design will be advantageous to improve strategic habitat conservation for the $\mathrm{ABB}$. We anticipate that improved datasets and more spatial analyses will improve our understanding of the conservation status of the $\mathrm{ABB}$ and will inform conservation planners of better strategies for recovery. In the future, greater emphasis will need to be placed on improving the overall quality of environmental datasets.

\section{ACKNOWLEDGEMENTS}

We thank P. Schmidt and M. Endries for initial peerreview, and three anonymous reviewers for comments that substantially improved the manuscript. The findings and conclusions in this article are those of the authors and do not necessarily represent the views of the U.S. Fish and Wildlife Service.

\section{CONFLICT OF INTEREST}

The authors confirm that this article content has no conflicts of interest.

\section{REFERENCES}

[1] United States Department of the Interior, Fish and Wildlife Service (USFWS) [Internet]. Summary of listed species, listed populations, and recovery plans 2012. [cited 2012 July 16] Available from: http://ecos.fws.gov/-tess public/

[2] United States of America. Congress. Endangered Species Act of 1973: as amended through the $108^{\text {th }}$ Congress. Congress 1973.

[3] Clark TW, Reading RP, Clarke AL, Eds. Endangered species recovery: finding the lessons, improving the process. Washington, D.C.: Island Press 1994.

[4] National Research Council (NRC). Science and the Endangered Species Act. Washington, D.C; National Academy Press 1995.

[5] Williams BK, Nichols JD, Conroy MJ. Analysis and management of animal populations. New York Academic Press: New York, 2002.

[6] McGowan CP, Ryan MR. Arguments for using population models in incidental take assessments for endangered species. J Fish Wildl Manag 2010; 1: 183-8.

[7] Wood MC. "You can't negotiate with a beetle": environmental law for a new ecological age. Nat Resour J 2010; 50: 167-210.

[8] National Ecological Assessment Team (NEAT) [Internet]. Strategic habitat conservation: final report of the National Ecological Assessment Team 2006. Available from: http://www.fws.gov/nces/habreg/NEAT_FinalRpt.pdf [cited 2012 July 18]

[9] Runge M. Strategic Habitat Conservation: making sense of acronyms. Refuge Update 2008; 5(3): 10-11.

[10] United States Department of the Interior, Fish and Wildlife Service (USFWS) [Internet]. Strategic habitat conservation: Landscape Conservation Cooperatives 2012. Available from: http://www.fws.gov/landscape-conservation/pdf/SHCLCCFactSheetJuly2012.pdf [cited 2012 July 16]

[11] Defenders of Wildlife. Keeping every cog and wheel: reforming and improving the National Wildlife Refuge System 2008. Available from: http://www.defenders.org/publications/keeping_every_ cog_and_wheel.pdf

[12] The Nature Conservancy (TNC) [Internet]. Conservation by Design 2006. Available from: http://www.conservationgateway.org/file/ conservation-design-framework-mission-success
[13] Boyd DT. Oklahoma oil: past, present, and future. Oklahoma Geol Notes 2002; 62: 97-106.

[14] State of Oklahoma. Oklahoma Corporation Commission. 2010 report on oil and natural gas activity within the state of Oklahoma. Oklahoma Corporation Commission; 2010. Available from: http://www.occeweb.com/og/annualreports.htm [cited 2012 July 27]

[15] State of Oklahoma. Oklahoma Mining Commission. Annual Report. Department of Mines; 2010. Available from: http://www.ok.gov/mines/Annual_Reports/index.html [cited 2012 July 27]

[16] Walton R. State moves into top 10 in wind power growth. Tulsa World 2011. Available from: http://www. tulsaworld.com/news/article.aspx? subjectid $=298 \&$ articleid $=2011070$ -

7_298_0_Crossc845297 [cited 2012 July 27]

[17] Oklahoma Climatological Survey (OCS) [Internet]. Statement on climate change and its implications for Oklahoma 2007. [cited 2012 July 18] Available from: http://www.forestry.ok.gov/Websites/forestry/Images/OK\%20Climatological\%20Survey\%20climat e statement.pdf

[18] United States Department of the Interior, Fish and Wildlife Service (USFWS) [Internet]. Rising to the urgent challenge: strategic plan for responding to accelerating climate change 2010. Available from: http://www.fws.gov/home/climatechange/pdf/CCStrategicPlan.pdf

[19] Intergovernmental Panel on Climate Change (IPCC) [Internet]. Climate change 2007: synthesis report. Available from: http://ipcc.ch/publications_and_data/ar4/syr/en/ contents.html [cited 2012 July 18]

[20] Manly BFJ, McDonald LL, Thomas DL, McDonald TL, Erickson WP. Resource selection by animals: statistical design and analysis for field studies. Kluwer Academic Publishers: NL, 2002.

[21] Bustamante J. Predictive models for Lesser Kestrel Falco naumanni distribution, abundance and extinction in southern Spain. Biol Conserv 1997; 80: 153-60.

[22] Guisan A, Zimmerman NE. Predictive habitat distribution models in ecology. Ecol Modell 2000; 135: 147-86.

[23] Seoane J, Vinuela J, Diaz-Delgado R, Bustamante J. The effects of land use and climate on red kite distribution in the Iberian peninsula. Biol Conserv 2003; 11: 401-14.

[24] Luoto M, Virkkala R, Heikkinen RK, Rainio K. Predicting bird species richness using remote sensing in boreal agricultural-forest mosaic. Ecol Appl 2004; 14: 1946-62.

[25] Guisan A, Thuiller W. Predicting species distribution: offering more than simple habitat models. Ecol Lett 2005; 8: 993-1009.

[26] Anderson SH, Gutzwiller KJ. Wildlife habitat evaluation. In: Braun $\mathrm{CE}$, Ed. Techniques for wildlife investigation and management. The Wildlife Society: Bethesda 2005; pp. 489-502.

[27] McDonald LL, Alldredge JR, Boyce MS, Erickson WP. Measuring availability and vertebrate use of terrestrial habitats and food. In: Braun CE, Ed. Techniques for wildlife investigation and management. The Wildlife Society: Bethesda 2005; pp. 465-88.

[28] United States Department of the Interior, Fish and Wildlife Service (USFWS). Endangered and threatened wildlife and plants; determination of endangered status for the American burying beetle (Final Rule). Fed Regist 1989; 54: 29652.

[29] Lomolino MV, Creighton JE, Schnell GD, Certain DL. Ecology and conservation of the endangered American burying beetles (Nicrophorus americanus). Conserv Biol 1995; 9: 605-14.

[30] United States Department of the Interior, Fish and Wildlife Service (USFWS) [Internet]. American burying beetle (Nicrophorus americanus) 5-year review: summary and evaluation 2008. Available from: http://ecos.fws.gov/docs/five_year_review/doc1968.pdf [cited 2012 July 16].

[31] Bedick JC, Ratcliffe BC, Hoback WW, Higley LG. Distribution, ecology, and population dynamics of the American burying beetle [Nicrophorus americanus Olivier (Coleptera, Silphidae)] in southcentral Nebraska, USA. J Insect Conserv 1999; 3: 171-81.

[32] Ehrlich PR, Ehrlich AH. Extinction: the causes and consequences of the disappearance of species. Random House: New York, 1981.

[33] Primack RB. Essentials of conservation biology. Sinauer Associates Inc., Saunderland, 1993.

[34] United States Department of the Interior, Fish and Wildlife Service (USFWS) [Internet]. Species fact sheet: American burying beetle 2011. Available from: www.fws.gov/south-west/es/Oklahoma.com [Cited 2012 July 16] 
[35] Lomolino MV, Creighton JC. Habitat selection, breeding success and conservation of the endangered American burying beetle Nicrophorus americanus. Biol Conserv 1996; 77: 235-41.

[36] Wilson DS. Nest-site selection: microhabitat variation and its effects on the survival of turtle embryos. Ecology 1998; 79: 1884-92.

[37] Dettmers R, Bart J. A GIS modeling method applied to predicting forest songbird habitat. Ecol Appl 1999; 9: 152-63.

[38] Martin TE. Abiotic vs. biotic influences on habitat selection of coexisting species: climate change impacts? Ecology 2001; 82: 175-88.

[39] Crawford PHC, Hoagland BW. Using species distribution models to guide conservation at the state level: the endangered American burying beetle (Nicrophorus americanus) in Oklahoma. J Insect Conserv 2010; 14: 511-21.

[40] Jaynes ET. Information theory and statistical mechanics. Phys Rev 1957; 106: 620-30.

[41] United States Department of the Interior, Fish and Wildlife Service (USFWS) [Internet]. American burying beetle Nicrophorus americanus range wide survey guidance 2012. Available from: http://www.fws.gov/southwest/es/Oklahoma/ABB__Add_Info.htm [cited 2012 July 16]

[42] Li W, Wang Z, Ma Z, Tang H. A regression model for the spatial distribution of red-crown crane in Yancheng Biosphere Reserve, China. Ecol Modell 1997; 103: 115-21.

[43] Manel S, Dias JM, Buckton ST, Ormerod SJ. Alternative methods for predicting species distribution: an illustration with Himalayan river birds. J Appl Ecol 1999; 36: 734-47.

[44] Manel S, Williams HC, Ormerod SJ. Evaluating presence-absence models in ecology: the need to account for prevalence. J Appl Ecol 2001; 38: 921-31.

[45] Fleishman E, Mac Nally R, Fay JP, Murphy DD. Modeling and predicting species occurrence using broad scale environmental variables: an example with butterflies of the Great Basin. Conserv Biol 2001; 15: 1674-85.

[46] Fleishman E, Mac Nally R, Fay JP. Validation tests of predictive models of butterfly occurrence based on environmental variables. Conserv Biol 2003; 17: 806-817.

[47] Wilson KA, Westphal MI, Possingham HP, Elith J. Sensitivity of conservation planning to different approaches to using predicted species distribution data. Biol Conserv 2005; 122: 99-112.

[48] Wisconsin Department of Natural Resources (WDNR) [Internet].Karner blue butterfly habitat conservation plan 2007. Available from: http://dnr.wi.gov/forestry/publications/karnerblue/rangemap.pdf [cited 2012 July 28]

[49] Magris RA, Destro GFG. Predictive modeling of suitable habitats for threatened marine invertebrates and implications for conservation assessment in Brazil. Braz J Oceanogr 2010; 58: 57-68. [cited 2012 July 18] Available from: http://www.scielo.br/pdf/bjoce/v58nspe $4 / a 08$ v58ns.pdf
[50] Creighton C, Schnell G. Short-term movement patterns of the endangered American burying beetle, Nicrophorus americanus. Biol Conserv 1998; 86: 281-7.

[51] Johnson CJ, Gillingham MP. Mapping uncertainty: sensitivity of wildlife habitat ratings to expert opinion. J Appl Ecol 2004; 41: 1032-41.

[52] Phillips SJ, Dudik M. Modeling of species distributions with maxent: new extensions and a comprehensive evaluation. Ecography 2008; 31: 161-75.

[53] Elith J, Burgman MA, Regan HM. Mapping epistemic uncertainties and vague concepts in predictions of species distribution. Ecol Modell 2002; 157: 313-29.

[54] Thomas CD, Cameron A, Green RE, et al. Extinction risk from climate change. Nature 2004; 427: 145-8.

[55] Thuiller W, Richardson DM, Pysek P, Midgley GF, Hughes GO, Rouget $\mathrm{M}$. Niche-based modeling as a tool for predicting the risk of alien plant invasions at a global scale. Glob Change Biol 2005; 11: 2234-50.

[56] Mawdsley JR, O'Malley R, Ojima DS. A review of climate-change adaptation strategies for wildlife management and biodiversity conservation. Conserv Biol 2009; 23: 1080-9.

[57] Wu XB, Smeins FE. Multiple-scale habitat modeling approach for rare plant conservation. Landsc Urban Plan 2000; 51: 11-28.

[58] Rubino MJ, Hess GR. Planning open spaces for wildlife 2: modeling and verifying focal species habitat. Landsc Urban Plan 2003; 64: 89-104.

[59] Heikkinen RK, Luoto M, Kuussaari M, Toivonen T. Modelling the spatial distribution of a threatened butterfly: impacts of scale and statistical technique. Landsc Urban Plan 2007; 79: 347-57.

[60] Nichols JD. Using models in the conduct of science and management of natural resources. In: Shenk TM, Franklin AB Eds. Modeling in natural resource management. Island Press: Washington D.C., 2001; pp. 11-34.

[61] Kearney M, Porter W. Mechanistic niche modeling: combining physiological and spatial data to predict species' ranges. Ecol Lett 2009; 12: 334-50.

[62] Buckley LB, Waaser SA, MacLean HJ, Fox R. Does including physiology improve species distribution model predictions of responses to recent climate change? Ecology 2011; 92: 2214-21.

[63] Phillips SJ, Anderson RP, Schapire RE.Maximum entropy modeling of species geographic distributions. Ecol Modell 2006; 190: 231-59.

[64] Phillips SJ. Transferability, sample selection bias and background data in presence-only modeling: a response to Peterson et al. (2007). Ecography 2008; 31: 272-8.

[65] Baldwin RA. Use of maximum entropy modeling in wildlife research. Entropy 2009; 11: 854-66.

[66] Girvetz EH, Zganjar C, Raber GT, Maurer EP, Kareiva P, Lawler JJ. Applied climate-change analysis: The climate wizard tool. PLoS ONE 2009; 4(12): e8320. 